\title{
NEWBORN CARE PRACTICES IN AN URBAN SLUM OF DELHI
}

\author{
MANJU RAHI, D. K. TANEJA, AMRITA MISRA, N. B. MATHUR ${ }^{\star}$, SURESH BADHAN
}

\section{ABSTRACT}

BACKGROUND: Despite efforts by government and other agencies, neonatal morbidity and mortality continues to be high in India. Among other reasons, newborn care practices are major contributors for such high rates. AIMS: To find out the newborn care practices including delivery practices, immediate care given after birth and breast-feeding practices in an urban slum of Delhi. SETTINGS AND DESIGN: Community based, cross-sectional survey in a resettlement colony (a type of urban slum). MATERIALS AND METHODS: Semi-structured, pre-tested schedule was used to interview 82 mothers of newborns in the study area. STATISTICAL ANALYSIS: Data was analyzed using Epi - info version 6.04. Fischer exact test and $\chi^{2}$ test were applied. A P value of less than 0.05 was considered significant. RESULTS AND CONCLUSION: More than half i.e. 26 (56.1\%) of home deliveries, which were mostly conducted by dais $(24,91.3 \%)$ or relatives in $4(8.7 \%)$ of home deliveries. Bathing the baby immediately after birth was commonly practiced in 38 (82.6\%) of home deliveries. Finger was used to clean the air passage in most of the home deliveries (29, 63\%). About $61 \%$ (28) of home delivered newborns were not weighed at birth. Rooming in was practiced in majority of the cases. A few of home delivered neonates (12) were given injection tetanus toxoid by unqualified practitioners. Use of clip, band or sterile thread to tie the cord and no application to the cord was significantly higher in institutional deliveries. Breast milk as the first feed was significantly more in institutional deliveries. There is an urgent need to reorient health care providers and to educate mothers on clean delivery practices and early neonatal care.

Key words: Home deliveries, newborn care, slum

Over the last three decades, the annual number of deaths among children less than 5 years old has decreased by almost a third. Although infant mortality has fallen in many developing countries over the past two decades, the rate of fall is slowing. One

Departments of Community Medicine and *Pediatrics, Maulana Azad Medical College - 110 002, India

Correspondence

Dr. Manju Rahi

C-1/19, Mianwali Nagar, Near Paschim Vihar,

New Delhi - 110087, E-mail: drmanju2003@yahoo.com reason is the contribution of neonatal mortality, which has remained fairly steady over this period.

As neonatal mortality contributes to over $64 \%$ of infant deaths in India, ${ }^{[1]}$ interventions to improve child survival must address the neonatal period. The World Health Organization guidelines for essential newborn care encompass cleanliness, thermal protection, initiation of breathing, early and exclusive breast feeding, eye care, 
immunization, management of illness and care of low birth weight infants. ${ }^{[2]}$

The current study was carried out to assess how far these guidelines are being implemented in an urban slum of Delhi.

\section{Study area}

The present study was carried out in an urban resettlement colony (a type of slum) situated in East Delhi, associated with Urban Health Centre of a medical college, from April to June 2005. The population in the area, as in all slums, is characterized by low-income group and a large section being migrant from other states and utilization of health facilities provided by qualified personnel is poor in this group. Since slums are known to have population with poor living standards, unhealthy behavior and practices, therefore the choice of the slum area, for the present study.

\section{MATERIALS AND METHODS}

All live births during this period, in the service area were followed up. Mothers of 82 neonates were interviewed within 1 week of birth using a semi-structured, pre-tested schedule containing both open-ended and close-ended questions pertaining to place and mode of delivery, care at birth, cord care, breast feeding practices and immunization.

\section{Statistical analysis}

Data were analyzed using Epi - info version 6.04. Fischer exact test and $\chi^{2}$ test were applied wherever applicable to find out significant difference between comparable groups. A $P$ value of less than 0.05 was considered significant.

\section{RESULTS}

\section{Socio-demographic characteristics}

The study population consisted mostly of Hindus $(77,93.9 \%)$. Joint family system was the pre-dominant type $(62,75.6 \%)$ and nuclear families accounted for $24.4 \%$ (20). Most mothers were educated up to primary level $(33,40.2 \%)$, followed by senior secondary $(28,34.1 \%)$ and graduate and above (5, $6.1 \%)$. Just literate and illiterate constituted $6.1 \%$ (5) and $13.4 \%$ (11) respectively.

\section{0}

Place of delivery, person conducting and mode of delivery

Home deliveries (46) were more common $(56.1 \%)$ as compared to institutional deliveries $(36,43.9 \%)$. Home deliveries were conducted by dais $(24,91.3 \%)$ or by relatives $(4,8.7 \%)$. Most of the deliveries $(80$, $90.2 \%)$ were normal vaginal deliveries and only $2(9.8 \%)$ were caesarian sections. Most of the babies $(81,98.8 \%)$ cried immediately after birth while $1(1.2 \%)$ failed to do so.

\section{Newborn care}

\section{Cleaning the baby}

Bathing the newborn immediately after birth seemed to be a common practice as a large section $(38,82.6 \%)$ of home delivered newborns were given a bath after birth.

\section{Clearing the respiratory passage}

Air passage was cleaned by using a finger in $29(63 \%)$ of home deliveries and in 14
(30.4\%) air passages were not cleaned at all.

\section{Eye care}

Eyes of the newborns were cleaned (wiped) by unsterile cloth or cotton in 14 (30.4\%) of home deliveries and by boiled and different cotton swabs for each eye in 1 (2.2\%) case, whereas in $15(32.6 \%)$ of home delivered newborns, eyes were not cleaned at all.

\section{Birth weight}

Of the home delivered babies, 18 (39.1\%) were weighed at birth compared to weighing in all cases of institutional deliveries.

\section{Rooming in}

Rooming in of babies was practiced more often in home deliveries than institutional deliveries.

\section{Immunization}

$B C G$, OPV and hepatitis $B$ vaccine were given to $8(17.4 \%)$ newborns that were delivered at home. Majority of this immunization was done at urban health centre, situated in the study area. In the institutional deliveries BCG and OPV were given to most of the newborns but hepatitis $\mathrm{B}$ vaccine was given only to $28(77.8 \%)$ babies. Surprisingly, 12 (26.1\%) home delivered newborns were given injection tetanus toxoid by unqualified practitioners of that area. This was on the recommendation of the dai conducting the delivery [Table 1].

\section{Care of the cord}

\section{Instrument used to cut the cord}

Out of 46 home deliveries, a new shaving
Table 1: Distribution of newborns according to the place of delivery and care given at birth

\begin{tabular}{|c|c|c|c|c|}
\hline $\begin{array}{l}\text { S. } \\
\text { No. }\end{array}$ & Care & $\begin{array}{l}\text { Home } \\
n=46\end{array}$ & $\begin{array}{c}\text { Institutional } \\
{ }^{*} n=36\end{array}$ & $\begin{array}{c}\text { Total } \\
n=82\end{array}$ \\
\hline \multirow[t]{5}{*}{1} & Cleaning the baby & & & \\
\hline & & $38(82.6)$ & & \\
\hline & Dry cloth / cotton & $1(2.2)$ & & \\
\hline & Wet cloth /cotton & $2(4.3)$ & & \\
\hline & Don't know & $5(10.8)$ & - & - \\
\hline \multirow[t]{5}{*}{2} & $\begin{array}{l}\text { Clearing the air } \\
\text { passage }\end{array}$ & & & \\
\hline & Finger & $29(63.0)$ & & \\
\hline & Mucus extractor & $0(0.0)$ & & \\
\hline & Not done & $14(30.4)$ & & \\
\hline & Don't know & $3(6.5)$ & - & - \\
\hline \multirow[t]{4}{*}{3} & Eye care & & & \\
\hline & $\begin{array}{l}\text { Cloth / cotton } \\
\text { Boiled and diff }\end{array}$ & $\begin{array}{l}14(30.4) \\
1(2.2)\end{array}$ & & \\
\hline & $\begin{array}{l}\text { swabs } \\
\text { Wiping with hands }\end{array}$ & $6(13.0)$ & & \\
\hline & Not done & $15(32.6)$ & & \\
\hline & Don't know & $10(21.7)$ & - & - \\
\hline & $\begin{array}{l}\text { Birth weight } \\
\text { Taken }\end{array}$ & & $36(100)$ & $54(65.8)$ \\
\hline & Not taken & $28(60.9)$ & $0(0.0)$ & $28(34.1)$ \\
\hline \multirow[t]{3}{*}{5} & Rooming in & & & \\
\hline & Present & $45(97.8)$ & $30(83.3)$ & $75(91.4)$ \\
\hline & $\begin{array}{l}\text { Absent } \\
\text { Immunization }\end{array}$ & $1(2.2)$ & $6(16.6)$ & $7(8.5)$ \\
\hline & BCG & $8(17.4)$ & 31 (86.1) & $39(47.5)$ \\
\hline & OPV & $8(17.4)$ & $32(88.9)$ & 40 (48.7) \\
\hline & Hepatitis B & $8(17.4)$ & $28(77.8)$ & $36(43.9)$ \\
\hline & Tetanus toxoid & $12(26.1)$ & $0(0.0)$ & $12(14.6)$ \\
\hline
\end{tabular}

${ }^{\star}$ A large proportion of mothers who delivered in the institutions were unaware of the care provided for items at S. No. 1, 2 and

blade was used to cut the cord in 36 (78.3\%) of home deliveries. Surgical blade available in the delivery kit was used in 5 cases. In one case each, old blade or a shaving razo or a kitchen knife was used to cut the cord.

\section{Cord tie}

Cord of the newborn was tied using a clip or a rubber band in institutional deliveries. Whereas sterile thread or clip (available in the delivery kit) was used only in $13(28.3 \%)$ o home deliveries, the difference being highly significant $(P<0.001)$. In rest of the cases threads, available at home, were used which 
can be presumed to be unsterile [Table 2].

\section{Applicant}

Nothing was applied to the cord, more in case of newborns born in the institutions (31, $86.1 \%)$ than at home $(29,63 \%)$. This difference was significant $(P<0.05)$. Povidine iodine or tincture iodine was applied in some cases $(3,3.6 \%$ of all newborns). Other applicants like turmeric with oil or ghee; just oil or ghee and cold cream were also applied in as much as 15 (32.6\%) home deliveries. These were applied in $4(11.1 \%)$ institutional deliveries not in the institution but after the child was brought home [Table 2].

\section{Breast feeding practices}

\section{First feed after birth}

First feed given to the baby after birth was breast milk in 11 (23.9\%) home deliveries and $16(44.4 \%)$ institutional deliveries. In other cases babies were given prelacteal feeds (39, $47.6 \%)$ such as ghutti (26.1\%), honey $(14.6 \%)$ or jaggery $(8.5 \%)$ or even top milk $(16,19.5 \%)$

Table 2: Distribution of newborns according to the place of delivery and cord care

\begin{tabular}{|c|c|c|c|c|c|}
\hline Cord care & $\lambda$ & Home $n=46$ & Institutional ${ }^{*} n=36$ & Total $n=82$ & $P$ value \\
\hline \multicolumn{6}{|c|}{ Instrument used to cut the cord } \\
\hline New blade & & 36 (78.3) & - & & \\
\hline Surgical blade & & $5(10.8)$ & & & \\
\hline Old blade & & $1(2.2)$ & & & \\
\hline Others & & $2(4.3)$ & & & \\
\hline Don't know & & $2(4.3)$ & - & - & - \\
\hline \multicolumn{6}{|l|}{ Cord tie used } \\
\hline $\begin{array}{l}\text { Sterile thread/clip/band } \\
\text { Unsterile thread }\end{array}$ & & $13(28.3)$ & $36(100.0)$ & $49(59.8)$ & $<0.001$ \\
\hline \multicolumn{6}{|l|}{ Cord applicant used } \\
\hline Nothing & & $29(63.0)$ & $31(86.1)$ & $60(73.2)$ & 0.036 \\
\hline Povidine iodine & & $1(2.2)$ & $1(2.8)$ & $2(2.4)$ & $\mathrm{DF}=1^{*}$ \\
\hline Tincture iodine & & $1(2.2)$ & $0(0.0)$ & $1(1.2)$ & \\
\hline Others & & $15(32.6)$ & $4(11.1)$ & 19 (23.2) & \\
\hline
\end{tabular}

\#A large proportion of mothers were unaware of the instrument used to cut the cord. Hence observation on this item was not included in the table, ${ }^{*}$ Nothing Vs rest makes it $2 \times 2$ table.

\section{Time of initiating breast feeding}

Breast feeding was initiated within 4 hours in only $34.8 \%$ of home deliveries (16) as against $44.4 \%$ of institutional deliveries (16). The difference was statistically not significant. In case breast-feeding initiated later than 4 hours, reasons for this were enquired into. Traditional practices such as baby to be fed on a starlit night or in the presence of a paternal aunt etc were cited as reasons in $26 \%$ of cases. It was dai's advice who conducted the deliveries in $14 \%$ of cases, no milk secretion (18.1\%), no knowledge regarding early breast feeding $(16 \%)$, mother was tired $(10 \%)$, post operative $(10 \%)$, staff instructions $(4 \%)$ or baby asleep/ didn't take feed (2\%) were the other reasons cited.

\section{Colostrum feeding}

Colostrum was given to the baby in 26 $(72.2 \%)$ hospital deliveries as against 32 $(69.5 \%)$ of home deliveries. Nearly $1 / 3^{\text {rd }}$ $(29.3 \%)$ of all newborns were not given

colostrums [Table 3].

Table 3: Distribution of newborns by place of delivery and breast-feeding practices

\begin{tabular}{lcccc}
\hline Breast-feeding practice & Home $n=46$ & Institutional $n=36$ & Total $n=82$ & $P$ value \\
\hline First feed after birth & & & & \\
Breast milk & $11(23.9)$ & $16(44.4)$ & $27(32.9)$ & 0.08 \\
Top milk & $10(21.8)$ & $6(16.7)$ & $16(19.5)$ & $\mathrm{DF}=2$ \\
Ghutti / honey/ jaggery & $25(54.3)$ & $14(38.9)$ & $39(47.6)$ & \\
$\begin{array}{l}\text { Time of initiating breast feed } \\
\text { Within } 1 \text { hour }\end{array}$ & $4(8.7)$ & $5(13.8)$ & $9(10.9)$ & 0.73 \\
$1-4$ hours & $12(26.1)$ & $11(30.5)$ & $23(28.0)$ & $\mathrm{DF}=3$ \\
$5-12$ hours & $14(30.4)$ & $11(30.5)$ & $25(30.5)$ & \\
$>12$ hours & $16(34.8)$ & $9(25.0)$ & $25(30.5)$ & \\
Discarding expressed colostrum initially & $14(30.4)$ & $10(27.7)$ & $24(29.3)$ & 0.98 \\
Yes & & & & $\mathrm{DF}=1$ \\
& & &
\end{tabular}

\section{DISCUSSION}

The present study was carried out in a resettlement colony (a type of slum area). Literacy level of mothers was high (71, $86.5 \%)$ and joint family system was predominant $(62,75.6 \%)$.

The proportion of institutional deliveries in the current study $(36,56.1 \%)$ is similar to that reported by National Family Health Survey II (NFHS-II) for Delhi. ${ }^{[3]}$

\section{Newborn care at birth}

In majority of home deliveries (38, 82.6\%), the newborn was bathed immediately after birth. Such a practice, reported elsewhere too ${ }^{[4]}$ should be discouraged as it can lead to hypothermia. Bathing the newborns in the first hour after delivery resulted in significantly increased prevalence of hypothermia in a randomized controlled trial conducted in Uganda. ${ }^{[5]}$ In 29 (63\%) home deliveries, finger was used to clear the air passage of the newborn by the birth attendant. This can lead to introduction of infection and injury. Unsterile cloth or cotton or even fingers were used in large proportion of cases to wipe the eyes of the newborn.
These unhygienic practices should be discouraged, as these can be a potential source of infection. Only a little more than one third of the newborns delivered at home were weighed at birth. Weighing at birth is an essential activity carried out to determine babies at higher risk and accordingly, determine need for extra care. Although weighing of newborns has been emphasized in Integrated Management of Neonatal and Childhood Illnesses (IMNCI) and training of dais, its importance may have to be emphasized to the would-be-mothers during antenatal period besides monitoring the work of dais to make weighing at birth universal. It was encouraging to find out that, rooming in was practiced in $75(91.4 \%)$ cases. Findings are similar to a previous study. ${ }^{[6]}$ As per the recommended immunization schedule BCG, OPV and hepatitis B vaccines were given to most of the babies at birth, in case of institutional deliveries. Even $17.4 \%$ (8) of the home delivered newborns were immunized with BCG, OPV and Hepatits $B$ within a day or two at the Urban Health Center in the area. It was revealing to know that 12 newborns $(26.1 \%)$ delivered at home were injected tetanus toxoid on the recommendation of the traditional birth 
attendant by unqualified practitioners. Mothers should be made aware of the correct and complete immunization schedule to enhance immunization coverage and to avoid such a malpractice.

\section{Care of the cord}

A new/ surgical blade was used to cut the cord in $41(89.1 \%)$ home deliveries. Such a good practice was found to be more common in the present study than earlier studies. ${ }^{[7,8]}$ Use of an old blade or a shaving razor or a kitchen knife calls for urgent intervention. Training of traditional birth attendant has been shown to be effective in reducing perinatal mortality. ${ }^{[9]}$ Antenatal mothers and family members (especially women) should be made aware of the adverse consequences of using such instruments for cutting the cord, during the antenatal period itself. In $33(71.7 \%)$ home deliveries, any thread available at home was used to tie the cord. Mothers should be educated to at least boil the thread before use. Application of oil or ghee with or without turmeric to the cord was common in home deliveries. It was surprising to observe that even in $4(11.1 \%)$ institutional deliveries, these were applied after the baby was brought home. Such a practice may predispose the newborn to risk of neonatal tetanus as topical application of ghee to the umbilical wound has been shown to pose a significant risk of neonatal tetanus. ${ }^{[10]}$ This issue should be discussed and clarified not only with mothers and family members but also with the birth attendant conducting the delivering as her advice to the family has serious implications on neonatal health.

\section{Breastfeeding practices}

About 27 (32.9\%) newborns were given breast milk as the first feed in the present study as compared to $47.5 \%$ in a study conducted in Ho Chi Minh City in Vietnam ${ }^{[11]}$ Although breast milk was the first feed was given to higher proportion of babies delivered in the institutions, the practice of pre-lacteal feeds in the form of ghutti, honey, jaggery water was still highly prevalent in both home and institutional delivered babies. The practice of pre-lacteal feeds is widely prevalent in India. ${ }^{[12,13]}$ Such a practice, by delaying initiation of breastfeeding, may adversely affect establishment of lactation ${ }^{[14]}$ and introduce enteric infections if pre-lacteal feeds are not given in hygienic manner. Although in the current study, colostrum was given to babies more commonly than other studies, ${ }^{[12,15]}$ still about one-third mothers had discarded colostrum, which needs to be stopped. Similar to other studies, ${ }^{[12,14,16]}$ most mothers in institutional as well as home deliveries did not initiate breast-feeding within one hour of birth. The protection provided by early initiation of breast-feeding against the risk of neonatal mortality was established in a study in rural Ghana. It showed that $16 \%$ of neonatal deaths could be averted if all infants were breast-fed from day 1 and $22 \%$ if breastfeeding started within the first hour. ${ }^{[17]}$ As the baby is most active during the first hour of birth and sucks more vigorously during this period, lactation is more likely to be successfully established if breastfeeding is initiated early. For popularizing such a practice, common reasons like quasi-religious rituals, ${ }^{[18]}$ not enough milk, ${ }^{[16]}$ ill health and fatigue of mother and lactation failure ${ }^{[15,19]}$ need to be addressed through suitable IEC and counseling. Besides health care providers conducting deliveries, should also focus on this aspect.

\section{Limitations of the study}

The study is based on reported newborn care and not based on actual observations. As a result response for some of the practices could not be obtained in case of institutional deliveries, as mothers were not aware of those. The survey is likely to have missed information on neonates who died before the visit of the investigator or were hospitalized. However, their number is likely to be very small.

\section{CONCLUSIONS}

Inspite of the fact that most of the mothers were literate, harmful newborn care practices were common. This can be attributed largely to dias as most deliveries were at home and harmful practices were observed most often in these cases. Besides traditions, community practices also seem to be important contributors as harmful practices were observed even in some institutional deliveries or after discharge from the institution. There is an urgent need to educate mothers and train health care providers including traditional birth attendants and anganwadi workers on newborn and early neonatal care. Various behavioral change communication strategies through mass media and interpersonal education during antenatal visits may be studied for their effectiveness. Prevailing unhealthy practices in the area also should be discussed with health care providers including dais and local practitioners, so that they take special action in preventing these.

\section{REFERENCES}

1. www.unicef.org/India/health. State of the World's Children. UNICEF: 2006.

2. World Health Organization. Report of the Division of Child Health and Development 1996-97. WHO: Geneva; 1998.

3. National Family Health Survey, India, Key Findings (NFHS-2), 1999. International Institute fo Population Sciences, Govandi Station, Deonar Mumbai -400088

4. Osrin D, Tumbahangphe KM, Shrestha D, Mesko $\mathrm{N}$, Shrestha BP, Manadhar MK, et al. Crosssectional, community based study of care of newborn infants in Nepal. BMJ 2002;325:1063-8.

5. Bergstrom A, Bvaruhanga R, Okong P. The impact of newborn bathing on the prevalence of hypothermia in Uganda: A randomized, controlled trial. Acta Paediatr 2005;94:1462-7.

6. Zhao Y, Niu AM, Xu GF, Garrett MJ, Greiner T. Early infant feeding practices in Jinan City, Shandong Province, China. Asia Pac J Clin Nutr 2003;12:104-8.

7. Nandan D, Mishra SK. Delivery practices in wes Uttar Pradesh. Indian J Public Health 1996;40:20-1.

8. Hoque A, Selwyn BJ. Birth practice in urban slums of Dhaka, Bangladesh. Women Health 1996;24:41 58.

9. Jokhio $A H$, Winter HR, Cheng KK. An intervention involving traditional birth attendants and perinatal and maternal mortality in Pakistan. N Engl J Med 2005;352:2091-9.

10. Bennett J, Azhar N, Rahim F, Kamil S, Traverso $\mathrm{H}$, Killgore $\mathrm{G}$, et al. Further observations on ghee as a risk factor for neonatal tetanus. Int J Epidemio 1995;24:643-7.

11. Li L, Thi Phuong L, Hoa NT, Ushijima H. Prevalence of breast feeding and its correlates in $\mathrm{HO}$ Chi Minh City, Vietnam. Pediatr Int 2002;44:47-54.

12. Singh MB, Haldiya KR, Lakshminarayana J. Infant 
feeding and weaning practice in some semi-arid rural areas of Rajasthan. J Indian Med Assoc 1997;95:576-8,590.

13. Deshpande SG, Zodpey SP, Vasudeo ND. Infant feeding practices in a tribal community of Meghlat region in Maharashtra state. Indian $\mathrm{J}$ Med Sci 1996;50:4-8.

14. Ahmed FU, Rahman ME, Alam MS. Prelacteal feeding: Influencing factors and relation to establishment of lactation. Bangladesh Med Res Counc Bull 1996;22:60-4.

15. Srivastava SP, Sharma VK, Kumar V. Breast feeding pattern in neonates. Indian Pediatr 1994;31:1079-82.

16. Banapurmath CR, Nagaraj MC, Banapurmath S,
Kesaree N. Breast feeding practices in villages of central Karnatka. Indian Pediatr 1996;33:477-9.

17. Badruddin SH, Inam SN, Ramzanali S, Hendricks $\mathrm{K}$. Constraints to adoption of apprpriate breast feeding practices in a squatter settlement in Karachi, Pakistan. J Pak Med Assoc 1997;47:63-8.

18. Edmond KM, Zandoh C, Quigley MA, AmengaEtego S, Owusu-Agyei S, Kirkwood R. Delayed breastfeeding initation increases risk of neonatal mortality. Pediatrics 2006;117:e380-6.

19. Mathur GP, Chitranshi S, Mathur S, Singh MB, Bhalla M. Lactation failure. Indian Pediatr 1992;29:1541-4.

Source of Support: Nil, Conflict of Interest: None declared.

\section{Author Help: Online Submission of the Manuscripts}

Articles can be submitted online from http://www.journalonweb.com. For online submission articles should be prepared in two files (first page file and article file). Images should be submitted separately.

1) First Page File:

Prepare the title page, covering letter, acknowledgement, etc., using a word processor program. All information which can reveal your identity should be here. Use text/rtf/doc/pdf files. Do not zip the files.

2) Article file:

The main text of the article, beginning from Abstract till References (including tables) should be in this file. Do not include any information (such as acknowledgement, your names in page headers, etc.) in this file. Use text/rtf/doc/pdf files. Do not zip the files. Limit the file size to $400 \mathrm{~kb}$. Do not incorporate images in the file. If file size is large, graphs can be submitted as images separately without incorporating them in the article file to reduce the size of the file.

3) Images:

Submit good quality colour images. Each image should be less than $\mathbf{1 0 0} \mathbf{~ k b}$ in size. Size of the image can be reduced by decreasing the actual height and width of the images (keep up to about 3 inches) or by reducing the quality of image. All image formats (jpeg, tiff, gif, bmp, png, eps, etc.) are acceptable; jpeg is most suitable. The image quality should be good enough to judge the scientific value of the image.

Always retain a good quality, high resolution image for print purpose. This high resolution image should be sent to the editorial office at the time of sending a revised article.

4) Legends:

Legends for the figures/images should be included at the end of the article file. 